[This document contains the author's accepted manuscript. For the publisher's version, see the link in the header of this document.]

\title{
Values and Ethics of Global Civil Society Actors: Insights from a Survey and Content Analyses
}

\author{
Mariya Y. Omelicheva
}

\section{Paper citation:}

Omelicheva, Mariya Y. Values and Ethics of Global Civil Society Actors: Insights from a Survey and Content Analyses, Journal of Civil Society 2(3):233-249, 2006.

\author{
Keywords: \\ Global civil society, norms, ethics, principles
}

\begin{abstract}
:
This study examines values, ethics, and principles of conduct that underlie activities of global civil society organizations. It uses an international web-based survey, and a content analysis of the codes of conduct for exploring views of global civil society actors active on global issues and participating in global civil society events. The findings of this analysis highlight many similarities in the ways global civil society organizations of different forms and origins define their goals, values, ethical standards, and responsibilities. The normative consensus discerned in this research is limited in scope, however. It revolves around a particular, liberal, view of civil society. The study discusses results of the survey and content analyses in light of the current debates on the nature of global civil society and its relation to the system of states and the global market.
\end{abstract}


Journal of Civil SocietyVol. 2, No. 3, 233-247, December 2006

\title{
ARTICLE
}

\section{Values and Ethics of Global Civil Society Actors: Insights from a Survey and Content Analyses}

\author{
MARIYA Y. OMELICHEVA* \\ "Department of Political Science, Purdue University, West Lafayette, IN, USA
}

\begin{abstract}
This study examines values, ethics, and principles of conduct that underlie activities of global civil society organizations. It uses an international web-based survey, and a content analysis of the codes of conduct for exploring views of global civil society actors active on global issues and participating in global civil society events. The findings of this analysis highlight many similarities in the ways global civil society organizations of different forms and origins define their goals, values, ethical standards, and responsibilities. The normative consensus discerned in this research is limited in scope, however. It revolves around a particular, liberal, view of civil society. The study discusses results of the survey and content analyses in light of the current debates on the nature of global civil society and its relation to the system of states and the global market.
\end{abstract}

KEY WORDS: Global civil society, norms, ethics, principles

\section{Introduction}

The rapid expansion of citizens' associations at the global level led many analysts to believe that global civil society (hereinafter, GCS) posed a viable empirical challenge to the state-centric mode of thinking and governance. Whether through the democratization 
of global politics, or the spread of a global ethic oriented toward human rights, sustainability, and the culture of peace, GCS has been seen as a potent force beyond deep transformations in the international realm (Baker \& Chandler, 2005). It has been viewed as an alternative to "the anarchical structure, inequality, and exclusions of the state system" (Pasha \& Blaney, 1998, p.418). To gauge the significance and potentialities of this civil alternative, we need to know what kinds of ethics, values, and principles of conduct underlie activities of GCS actors. Do GCS actors believe in the inclusiveness and equality of GCS? What kinds of values do they share? Do they have a common understanding of their responsibilities?

These questions merit academic attention for a variety of reasons. For one, the creation of more representative, accountable, legitimate, and transparent global civil society hinges, among other things, on the existence of coherent and consensual values, ethics, and operating principles underlying activities of GCS agents. The literature, however, lacks systematic analyses of norms and ethical principles of GCS organizations. Global Civil Society Index (GSCI) is one of the latest notable attempts to summarize the contours of GCS by identifying and taking measures on a manifold of parameters of associational life (Anheier \& Stares, 2002, p.243-44). Regrettably, the GSCI reduces norms and ethics of GCS to individuals' cosmopolitan values such as 'tolerance'. The values, ideas, norms, and principles governing the conduct of civil society organizations are left out of the index.

From the theoretical perspective, the survey of norms and ethics of GCS actors can assist in developing and testing a theory of the socio-genesis of global civil society in relation to the system of states and the global market. The inquiry into the normative and 
ethical aspects of civil life at the global level can provide valuable insight into the development of self-understanding, consciousness-creation, and identity of the members of GCS.

As a step toward discovering normative and ethical contours of GCS, this study is set to examine values, norms, and principles of conduct of a slice of GCS actors by means of the web-based questionnaire and the content analysis of normative documents, such as codes of conduct, ethics, guidelines, and principles adopted by GCS organizations at the national, regional, and international levels (hereinafter, codes of conduct). The purpose of the survey- and content-analysis is to develop an understanding of how GCS organizations, themselves, conceive of the space where their activities take place, and what their goals and values are. The questionnaire taps into the questions of values, responsibilities, and standards for integrity and performance of the surveyed organizations. The systematic analysis of the codes of conduct is designed to complement the survey and triangulate respondents' self-reports.

The study is composed of four sections. The first section describes the survey methodology and a framework for examining the codes of conduct. The second section discusses findings revealed through the analysis of the survey responses and written documents of GCS organizations. In the third section, I integrate empirical findings of the study with the existing theoretical knowledge on GCS to suggest ways in which the collected evidence can contribute to current debates about the nature of GCS and its role in global governance. In conclusion, I provide an overview of the study and suggest avenues for future investigation. 
Journal of Civil SocietyVol. 2, No. 3, 233-247, December 2006

\section{Research Design}

To explore values, ethics, and principles of conduct of GCS actors, I used a survey of GCS organizations and a content-analysis of their codes of conduct. The codes are public statements of principles and minimum standards of performance to which GCS

organizations declare their commitment, and against which their activities can be evaluated. The content analysis of these statements can reveal norms, values, and principles shared by signatories of the codes.

I designed a web-based questionnaire (in English) and distributed it among 250 organizations active on global issues and participating in GCS events. The survey was posted on the Internet using Hosted Survey, an Internet company that supports web based surveys and provides confidential services to protect the integrity of the study. I also content-analyzed 40 codes of conduct endorsed by over 7,000 local and international organizations, and more than 150 federations and networks representing 5,700 GCS actors from more than 160 states.

A sampling frame for the survey included all civil society organizations registered in the following databases: Idealist, a project of Action Without Borders, ${ }^{1}$ InterActions: Links to NGOs worldwide, ${ }^{2}$ and NGOnet. ${ }^{3}$ Idealist is one of the respected sources for research on civil society organizations, activities, and projects. Its data-base contains information on over 56,000 non-governmental organizations from 165 countries. InterActions is an alliance of 165 US-based international development and humanitarian NGOs working in every developing state of the world. NGOnet is an electronic networking resource for NGOs in Central and Eastern Europe and the former Soviet Union. 
With an interest in examining perspectives of global civil society actors across the globe, I chose to rely on a proportional stratified sampling technique to draw a more representative sample that might be expected under simple random sampling. ${ }^{4}$ I divided the sampling frame of GCS organizations into two groups: (1) Northern GCS organizations, located in the high-income states (according to the World Bank country classification); and (2) Southern GCS organizations, located in the low- and middleincome states. The former group included approximately 48,200 GCS groups pooled from the Idealist and InterAction databases. The second group contained about 8,200 organizations pooled from Idealist and NGOnet. Idealist search engine returns civil society groups organized by state in which there are located, and region.

I used a table of random numbers to draw a sample of 125 GCS actors from each group. The Idealist and NGOnet databases contain records of community-based, national, as well as international organizations. Since the goal of this study is to survey views of GCS actors, I excluded from the sample those organizations serving a specific population in a narrow geographical area. At the time of the study, Idealist used a verification system to ensure that employees of an organization registered in the database are responsible for their organization's page on Idealist. Those organizations that were not verified by the Idealist team, did not have email contact in the database, or had an invalid contact were not included into the sample.

I sampled 250 GCS actors: 47 - from Africa, 65 - from Europe (including 24 from Eastern Europe), 38 - from Asia, 10 - from Middle East; 38 - from Latin America and Caribbean, 41 - from US and Canada, and 11 - from Australia and Pacific. A half of the sample represents GCS organizations located in the high-income states, and another 
half - in low- and middle-income states. The sample varies with regard to the types of organizations and types of activities. It includes non-governmental organizations (NGOs), charities, research institutions, networks, and voluntary associations working in the areas of economic development, human rights, social services, education, culture, and environment.

To identify the codes of conduct for the present analysis, I relied on the collection of Codes of Conduct for Partnership in Governance prepared for the World Civil Society Conference (WOCSOC) under the aegis of the United Nations University (Kunugi \& Schweitz, 1999). This volume contains the most comprehensive, albeit non all-inclusive, collection of documents. It illustrates the foundational efforts of GCS actors to build partnerships, and identify principles and standards of performance to which they voluntarily sign up. I examined all valid codes from the collection of Codes of Conduct for Partnership in Governance, and augmented the sample with a number of national, regional, and international codes that I was able to find on the Internet. The collected sample represents a wide range of documents adopted under different titles (codes, guidelines, principles, etc.) in different sectors of activity (charities, cooperatives, credit unions, businesses, disaster relief, human rights and development, etc.).

The questions for the survey and content-analysis were developed on the basis of extensive screening of the existing empirical and theoretical work concerned with the normative aspects of GCS (Benchmark Environmental Consulting, 1996; DOSA, 2004; Pianta \& Silva, 2003). The survey questionnaire contained a series of questions about values, ethics, and operating principles of the surveyed organizations. Some questionnaire items were designed to acquire a better understanding of how the 
organizations conceive of the space where their activities and interactions take place and whether they agree on the nature of GCS actors. The content analysis asked the same kinds of questions of organizations' codes of conduct (see Appendix 1). The systematic analysis of documents was designed to complement findings of the survey and triangulate respondents' self-reports.

\section{Empirical Analysis of the Survey Reponses and Codes of Conduct}

The empirical analysis presented in this section is organized around the following themes. I begin by discussing how GCS organizations view themselves and the global environment in which they operate. Then, I consider the values and ethics transpiring in the language of codes and answers of respondents. Lastly, the rules of governance and operating principles of GCS organizations are examined. The survey results reported in the paper are based on the replies of 89 organizations responded to a one-time invitation to participate in the survey ( $37 \%$ response rate). The sample of respondents is broadly representative of all continents, types of organizations, and types of activities. Respondents to the questionnaire are located for $17 \%$ in Africa, $18 \%$ in Europe, $18 \%$ in Asia and Middle East; $17 \%$ in Latin America and Caribbean, $16 \%$ in US and Canada, and $3 \%$ in Australia and the Pacific.

There are thousands of groups that would qualify as operating within GCS. There are hundreds of codes that regulate activities of GCS organizations. It is extremely difficult, if not impossible, to identify and converse with a truly representative segment of GCS. Although, the analysis of the survey responses and codes of conduct do not necessarily characterize the reality of GCS, the insights of 89 organizations and 40 codes 
of conduct endorsed by thousands of groups active in global politics can be very instructive. The findings provide for a better understanding of how GCS actors view themselves and the space where their activities take place. I offer conscientious interpretations of the survey responses and provisions of codes keeping in mind that all surveyed organizations and the majority of codes' signatories are relatively progressive 'civil' organizations that have access to the Internet and are literate in English communication.

Characteristics of GCS actors. The examined codes of conduct tend to underscore a number of features of GCS actors (see Figure 1): (1) 22.5\% characterize GCS actors as voluntary, i.e., membership in these organizations should not be legally required, and organizations' human and material resources should come from voluntary contributions of time and money; (2) 35\% describe GCS actors as autonomous (or explicitly nongovernmental), i.e., uncontrolled by a governmental or commercial entity; (3) $20 \%$ define GCS actors as non-for-profit, meaning that profit making should play a secondary and subsidiary role in a spectrum of activities of global civil society organizations, and profits received from commercial activities should not be distributed for the enhancement of members', boards', staffs', or stakeholders' benefit; (4) 25\% emphasize the 'legality' and ‘civility' of GCS actors, i.e., GCS organizations should not get involved in illegal or violent activities; and (5) 40\% stipulate that GCS organizations should have some institutional presence and structure expressed in a well-articulated mission, policies, and governing structure of a GCS organization. Additionally, $15 \%$ of the codes portray GCS actors as non-political or non-partisan, and 5\% characterize them as non-self-serving. 


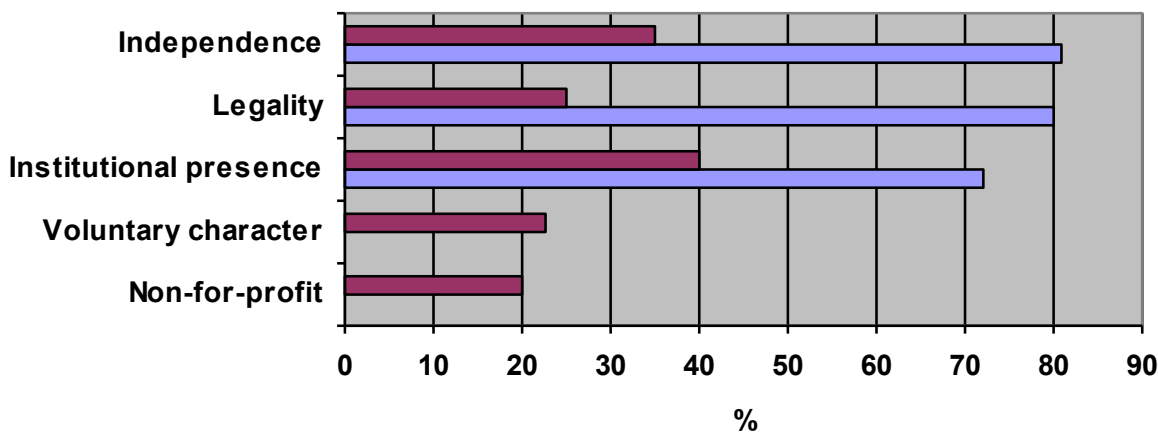

$\square$ Codes

$\square$ Survey responses

Figure 1. Characteristics of GCS Actors

Among the survey respondents, $81 \%$ believe that GCS organizations should be independent of governments, intergovernmental institutions, or corporate interests. About $80 \%$ support the legality of GCS actors, and nearly $72 \%$ underscore the importance of having an organizing document, an executive board, officers, and regular meetings and activities. The questionnaire did not contain questions about the voluntary and non-forprofit nature of GCS organizations.

Characteristics of global civil society. According to the signatories of the examined codes of conduct, GCS should exhibit the following characteristics (see Table 1): (1) the equality of GCS actors $(17.5 \%$ of the documents convey a desire of their signatories to operate in the environment where all actors are equal in various respects); (2) the diversity of actors (20\% of the documents appeal to diversity); (3) the commonality of values $(37.5 \%$ of the documents emphasize common values that enhance the sense of community of GCS organizations; (4) a common understanding of duties and responsibilities of GCS organizations (57.5\% of the documents); and (5) the atmosphere of cooperation and partnership among civil society actors (55\%). That GCS should embrace a culture of non-violence and solidarity is promoted in $35 \%$ and $37.5 \%$ of the 
codes correspondingly. Additionally, $30 \%$ of the codes envision GCS as a space of the reign of justice.

Table 1. Characteristics of GCS

\begin{tabular}{lcc}
\hline & $\begin{array}{c}\text { What qualities should GCS } \\
\text { exhibit? } \\
\text { (\% of codes) }\end{array}$ & $\begin{array}{c}\text { What qualities does GCS } \\
\text { lack? } \\
\text { (\% of survey responses) }\end{array}$ \\
\hline $\begin{array}{l}\text { Equality of GCS actors } \\
\text { Diversity of GCS actors }\end{array}$ & 17.5 & $41^{\mathrm{a}}$ \\
$\begin{array}{l}\text { Commonality of values } \\
\text { Common understanding of } \\
\text { duties and responsibilities } \\
\quad \text { of GCS actors }\end{array}$ & 20 & 47.5 \\
Atmosphere of cooperation & 57.5 & 54 \\
and partnership among GCS & & \\
$\quad$ actors & 55 & 64 \\
Culture of non-violence & & \\
Culture of solidarity & $35^{\mathrm{c}}$ & \\
$\mathrm{a}=$ The respondents were asked about whether they felt constrained by larger NGOs \\
$\mathrm{b}=$ This is a percentage of respondents who felt that GCS lacked a balanced presentation \\
of GCS actors from across the globe. \\
$\mathrm{c}=$ The respondents were not asked about the culture of non-violence and solidarity.
\end{tabular}

When asked to check all of the features that GCS is still lacking, $71 \%$ of the survey respondents admitted that GCS lacks a balanced representation of GCS organizations; $47 \%$ of the respondents believe that it lacks a set of common values, ideas, and principles; $55 \%$ say that it lacks coherent agenda and common vision of global mission; $54 \%$ see the lack of common understanding of duties and responsibilities of GCS actors; and $64 \%$ think that there is not enough cooperation among GCS actors.

In contrast to the expressed qualities of justice and equality, $41 \%$ of the surveyed respondents feel that their organizations are being constrained by larger NGOs, $16 \%$ - by Northern NGOs, $15 \%$ - by white-run NGOs, $12 \%$ - by English-language run NGOs, and $44 \%$ do not feel constrained. The only significant variation among the groups of the 
surveyed organizations of different geographical origins is that concerning larger NGOs. Sixty per cent of the participants from Africa think that their organizations have experienced being constrained by larger NGOs. In comparison, 30-35\% of the European, Latin American, Asian, and North American respondents share this perception.

Values of GCS actors. Both the codes of conduct and the survey responses reveal considerable agreement on certain key values of GCS organizations such as respect for individual human rights and freedoms $(96 \%$ of the surveyed organizations and $70 \%$ of the codes affirm their respect for individual human rights and freedoms), and respect for culture and history $(92 \%$ of the survey respondents and $40 \%$ of the codes express appreciation of cultural and contextual differences). Other values, such as respect for life, tolerance, humanity, and human-centeredness have also been mentioned in the codes.

Many documents articulate the allegiance of their signatories to human rights of different categories of people: $50 \%$ of the codes invoke women's right or greater gender equality; $25 \%$ - the rights of minorities; $15 \%$ - the rights of children and youth; $12.5 \%$ the rights of indigenous people; and $10 \%$ - people with disabilities. The value of participatory democracy is noted in $37 \%$ of the codes.

There is a great degree of variation in the amount of details in the codes' descriptions of values of GCS actors. Some codes, for example, supplement provisions about the respect for cultural and historical differences with reservations about noncompliance with traditional practices that can harm the individual and the community. Other documents allow for discrimination on the basis of religious beliefs in the faithbased organizations. 
Interestingly, $25 \%$ of the examined codes stress the importance of respect not only for the culture of communities, in which GCS actors operate, but also for the culture and values of other actors of GCS. The provisions of some codes dedicated to the conduct of Northern NGOs in the South stipulate that their 'life-style' should be appropriate to the national contexts as well as to their Southern partners, and that their approaches to work with the Southern organizations should be sensitive to the history of colonialism.

Ethics of GCS actors. A vast majority of survey respondents and the majority of codes acknowledge and consent that GCS organizations should be transparent and accountable (see Figure 2). Over $93 \%$ of the survey respondents believe that 'good' GCS organizations should be (1) open and transparent regarding their mission and objectives, values and principles, governance, partnerships, funding, programs, and means to achieve their objectives; and (2) accountable to funding agencies, government, and to the people they serve. More than $86 \%$ of the respondents believe that global civil society organizations should avoid taking actions that might have adverse effects on the peoples, communities, and natural resources. Only $69 \%$ of organizations participating in the survey consider that respect of the law of any jurisdiction in which they operate is one of the responsibilities of a GCS organization.

Among the codes, $60 \%$ of the documents deliver clear statements about the principles of transparency of GCS organizations, and 55\% - about their accountability. Slightly above $30 \%$ of the codes highlight the importance of avoiding activities that might have adverse effects on the people and ecology, and the same percentage of codes stress that GCS organizations should respect the legal systems in which they operate. With regard to the latter, some codes lay emphasis on the observance of tax and trade 
laws. Others specify that the respect of jurisdiction extends toward laws adopted in democratic societies and/or by legitimately constituted authorities.

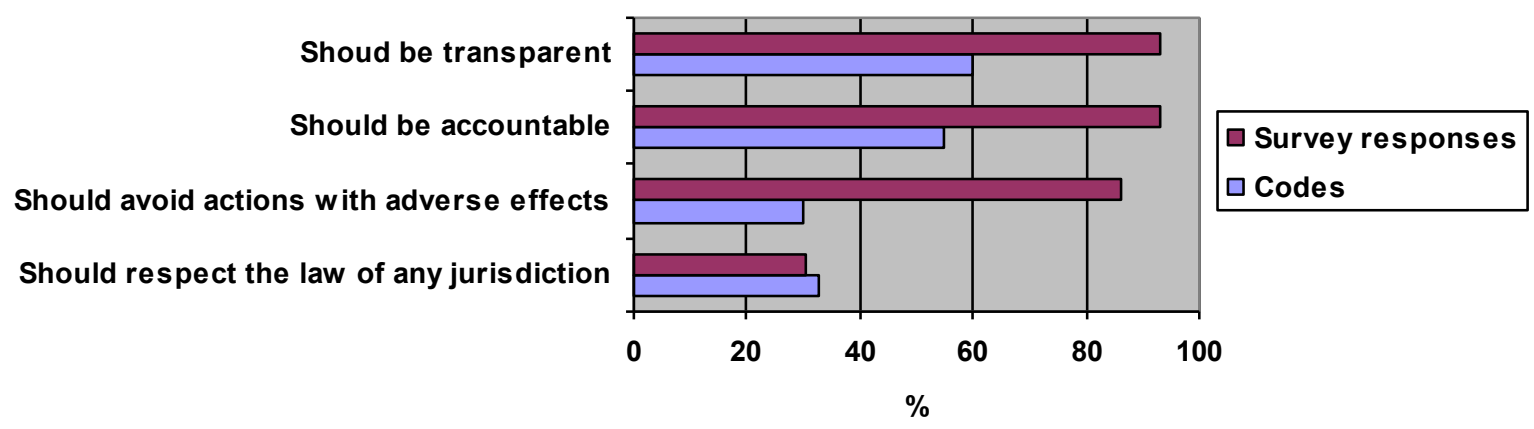

Figure 2. Ethics of GCS actors

Governance and operating principles of GCS organizations. As indicated above, $40 \%$ of the codes require GCS actors to have an identifiable governing structure. There is a significant variation as to what kinds of governing and administrative bodies and what types of written documents and policies GCS actors should have. A notable trend that emerged from the analysis of codes is that an increasing number of documents include sections on human resources and human management that set standards with regard to organizations' employees, volunteers, staff, and members of the governing bodies. Over $40 \%$ of the codes contain more or less thorough rules concerning the conduct of individuals in the situations of the conflict of interest, and $25 \%$ require a certain degree of competency, professionalism, and dedication from people involved in organizations' operations.

One of the recurrent principles of GCS programs is that of sustainability. The issue of environmental sustainability of projects, i.e., how project activities affect the quality of water, air, soil, and natural resources, is addressed in $32.5 \%$ of the codes. The 
principle of economic sustainability, i.e., how recurrent costs associated with project activities will be met, is mentioned in $47.5 \%$ of the codes. The principle of political sustainability, i.e., how project-supported innovations will be accommodated within the framework of existing laws, politics, and political institutions, transpires in $17 \%$ of the codes, and cultural sustainability, i.e., how project-supported innovations fit within the framework of existing norms, values, roles, and practices, in $15 \%$ of the codes (see Table 2).

Asked whether they follow any of the listed operating principles, only $69 \%$ of the surveyed organizations reported that they give adequate attention to environmental sustainability, and only $63 \%$ pay adequate heed to political sustainability. The most vigilant consideration is given to the questions of cultural sustainability and economic sustainability with 85 and $80 \%$ of the respondents reporting that their organizations deliberate over these questions throughout the project cycle.

The codes of conduct describe various accountability mechanisms, the most common being social or professional audit of an organization's finances (27.5\%), regular public reports on all activities that the organization has undertaken to realize its mission (27.5\%), and financial reports (15\%). The codes also stipulate a number of responsibilities concerning the involvement of all interested parties, including beneficiaries of the programs, and donors, into the development, implementation, and assessment of programs. Thus, $17 \%$ of the codes require their signatories to ensure the involvement of stakeholders on all stage of the organizations' programs, and $42.5 \%$ of the codes require that their signatories share information on the progress in achieving the 
organizations' missions through communications with their constituency and general public.

Table 2. Operating principles of GCS actors

\begin{tabular}{ccc}
\hline & $\begin{array}{c}\text { What principles should } \\
\text { underlie activities of GCS } \\
\text { actors? } \\
\text { (\% of codes that refer to an } \\
\text { operational principle) }\end{array}$ & $\begin{array}{c}\text { Do GCS actors follow the } \\
\text { operating principles? } \\
\text { (\% of survey respondents } \\
\text { who reported that their } \\
\text { organizations followed an } \\
\text { operational principle) }\end{array}$ \\
\hline $\begin{array}{c}\text { Environmental } \\
\text { sustainability }\end{array}$ & 32.5 & 69 \\
Political sustainability & 47.5 & 63 \\
Economic sustainability & 17 & 85 \\
Cultural sustainability & 15 & 80 \\
Communications with all & 42.5 & 86 \\
interested parties & & 64 \\
Regular public reports on & 27.5 & \\
all activities that an \\
organization has
\end{tabular}

Having expressed the believe in openness, transparency, and accountability as a normative imperative of civil activity, $86 \%$ of the survey respondents report that they routinely share information on the progress in achieving their mission through communications with constituency and general public; $76 \%$ give a regular financial account that include information on the sources and use of funds; $64 \%$ prepare regular (no less than once a year) public reports on all activities undertaken to realize their mission, and post information on partnerships and other joint ventures; and $60 \%$ publish full information about the governing body and officers. Less common mechanisms of accountability are peer reviews (33.3\%), social audit (36\%), complaint procedures (32\%), and evaluations of those organizations try to help (54\%). 
The analysis of the survey responses and the codes of conduct highlight many similarities in the ways GCS organizations of different forms and origins define their values, ethical standards, and operational principles. The majority of the surveyed organizations and codes express commitment to human rights and respect for cultural and historical differences. These values of GCS organizations support and reinforce commitments already proclaimed in the UN Declaration of Human Rights, to which $20 \%$ of the codes make direct references. The majority of respondents and codes stress the principles of transparency and accountability of GCS organizations to different constituencies.

The values and ethics of the surveyed organizations are generally consistent with those expressed in the language of codes. The percentages of support for different ethical and operational principles are somewhat higher among the survey respondents than in the codes. This can be attributed to the diversity of the examined documents and differences in the goals that they pursue. The discrepancy in figures can also be due to somewhat inflated self-assessment of the surveyed groups. There is an unavoidable tendency of selfenhancement in personal evaluations. In the organizational context, it is translated in an unreasonably favorable appraisal of one's organization. The biases of self-evaluation can be detected by comparing the evidence from self-reports with the reports of the thirdparties or peer evaluations. Unfortunately, GCS organizations are reluctant to criticize each other publicly, except when at polar extremes on a particular issue; consequently, peer reviews are in rare use among them. For example, among the surveyed organizations, peer review was the least used mechanism of accountability. 
Journal of Civil SocietyVol. 2, No. 3, 233-247, December 2006

\section{Views and Aspirations of GCS Actors: Reading through the Lens of Contemporary Debates on Global Civil Society}

Global civil society has been subjected to extensive conceptualization, theorization, and analysis in recent years. Yet, it remains a hotly contested term inscribed with descriptive as well as normative meanings. The rich and complex literature on GCS is permeated with debates about the nature and future of the socio-political processes unfolding at 'above' the state level (Amoore \& Langley, 2004, p.96; Baker \& Chandler, 2005; Bartelson, 2006; Buzan, 2004, p.79; Colás, 2005, p.18; Kaldo, 2003, p.11). This section looks at the responses and statements of GCS actors through the prism of the current debates concerning the reality of GCS and its normative features. This exercise is meant to link the findings of this study to the fields of theoretical and empirical knowledge on GCS, and suggest ways in which the collected evidence can contribute to the current discussion of GCS and its role in global governance.

The literature on GCS depicts it as the 'arena', the 'realm', the 'space', or the 'context' of regularized interactions of societal units (Cohen \& Arato, 1993, p.xviii; Colás, 2002; Edwards, 2001, p.2; Nardin, 2000, p.29; Scholter, 1999, p.10; Shaw, 1994, p.648; Walzer, 1995, p.7; Warkentin, 2001, p.1). These aphorismatic descriptions indicate that GCS has spacial boundaries. As a space, it is metaphorically located somewhere between the system of states, and the global market.

The place of GCS vis-à-vis the system of states and the global market has been a subject of much scholarly debate (see, e.g., Amoore \& Langley, 2004, p.92; Falk, 1998, 100; Kenny \& Germain, 2005, p.6). Some argue that GCS possesses a discrete raison d'être, which marks it out as different as well as autonomous from the system of states 
and from the global market (Chandhoke, 2002, p.36; Cohen \& Arato, 1992, p.18; Falk, 1998, 100; Lipschutz, 1992, pp.392; Taylor, 1991, p.171; White, 1994, p. 379).

Others maintain that the depiction of GCS as a bounded space obscures the extent to which GCS, the system of state, and the market economy are intertwined and mutually constituting (Amoore \& Langley, 2004, p.93). GCS is viewed as the correlate of the practices of states, which provide capacity, ability, and power that GCS needs to emerge and thrive (Bartelson, 2006, p.381; Naidoo and Heinrich, 2000, p.8). It is also portrayed as a product of globalization driven by capitalist forces (Buzan, 2004, p.84; Colás, 2002, p.7; Rosenau, 1998).

A number of findings of this study speak to the theme of GCS's spacial boundaries. Among the examined codes, 35\% envision independence of GCS actors from states and economic institutions, and $81 \%$ of the survey respondents believe that GCS organizations should be independent of governments, intergovernmental institutions, and corporate interest. When asked whether GCS is, in fact, independent, almost $78 \%$ of the surveyed organizations expressed a view that, in reality, GCS is not independent of the system of states and the global market. States and other institutions of governance provide, inter alias, legal and normative frameworks institutionalizing GCS's normative prerequisites (Amoore \& Langley, 2004, p.93). The institutions of economic globalization work only with those actors, which exhibit characteristics consistent with their understanding of GCS organizations (Howell \& Pearce, 2000; Seckinelgin, 2002).

There are numerous avenues through which governments and international financial institutions can circumscribe activities of GCS actors. The "politics of accreditation' adopted by international forums and inter-governmental organizations, 
compacts with governments, and business-like operational principles advance a particular understanding of GCS, the one privileged by the powerful states and institutions of economic globalization (Colás, 2002, p.151). It is noteworthy that the majority of organizations that admitted the lack of independence of GCS also reported that they have taken part in global forums and signed compacts with governments and businesses. Almost $72 \%$ of the survey respondents and $40 \%$ of the codes expressed support for an 'organizational' understanding of GCS actors, the one advocated by states and international financial institutions. In other words, despite the mentioning of pluralism and diversity, the majority of the surveyed organizations and a large number of codes take organizations and associations with a well-articulated mission, a governing body, and written policies as the locus of GCS action.

The principles of human rights, legality, plurality, and voluntary association endorsed by the survey respondents and signatories of the codes resonate with the liberal tradition of civil society promoted by the leading states and institutions of economic globalization. The fact that the majority of respondents agreed to underwrite liberal values and principles is unsurprising given that all respondents are relatively progressive transnational non-governmental groups capable of maintaining electronic correspondence in English. Yet, the endorsement of liberal principles by thousands of the codes' signatories from across the globe raises important questions about the relationship of GCS and states. Is GCS merely a tool for tightening of the grip of leading states (Kenny \& Germain, 2005, pp.10-11)? Is commitment to liberal ideas necessary for GCS organizations to succeed in global politics, i.e., do the achievements of civil society actors pivot on their endorsement of the values and norms of the most powerful states? 
Or, the relationship is reverse, i.e., the agents of global civil society, the carriers of liberal ideas, shape the behavior of states in the direction of greater recognition of liberal values and ideals?

Not only did the majority of respondents and codes of conduct underwrite liberal values, they also expressed support for a liberal perspective on the role of GCS in global governance. In the liberal perspective, the role of civil society is viewed as an aid to the state and as its monitor (Grugel, 2002, pp. 94-5). GCS is supposed to mediate and balance the power of the state and the market, provide an arena for citizens' participation in various voluntary associations at the global level, and offer a space for the development of democratic values (Dryzek, 1996, p.481; Gordenker \& Weiss, 1995, p.19; Howell \& Pearce, 2000, p.76; Lipschutz, 2005, p.10). Among the surveyed organizations, $71 \%$ of the respondents agreed that the purpose of global civil society is to increase the responsiveness of political institutions, and $61 \%$ agree with a cooperative strategy of the creation of a more supportive climate by facilitating partnerships with political institutions.

Among the participants of the survey, there were small minorities disagreeing with the majority's opinions on the values, goals, and strategies of GCS organizations. For instance, almost $10 \%$ of the respondents agreed to underwrite neo-liberal platform, and $25 \%$ agreed to grant support for globalization and humanization of the capitalist system. Seventeen percent of the survey respondents agreed that GCS's goal is to minimize the role of the state. The diversity of interests and agendas that exist within GCS has been well documented in the GCS literature (see, for example, Chandhoke, 2002, p.50; Naidoo \& Neinrich, 2000, p.9). The consensus on goals and values of GCS 
actors may not be as important as the presence of representative mechanisms for involving all GCS groups in decision making, and the means of reconciliation of different opinions and interests. The recognition of alternative views can legitimize political decisions, and forestall social conflict. The protection of minority views from the potential tyranny of the majority is essential to democratic governance.

A corollary of the present analysis is that the majority of the survey respondents and signatories of the codes recognize a rather narrow range of alternatives that fall within the liberal paradigm of civil society. The kinds of values that the survey participants agreed to endorse and those conveyed in the language of codes do not, however, reflect all of the contexts for which GCS actors purport to speak (Scholte, 2001, p.21). The 'voluntary' and 'civil' characteristics of GCS actors that the surveyed organizations and signatories of the codes agreed to endorse conceal the 'dark' side of GCS, where 'uncivil' and non-progressive actors engage in 'illegitimate' and, often, violent politics. The respondents' views on the lack of a balanced presentation of GCS organization from all over the world represent a tip of the iceberg of power-differentials that exist within GCS, and affect agendas, strategies of GCS organizations, and outcomes of their solidarity (An-Na'im, 2002, p.57).

\section{Conclusion}

I undertook this study to seek out an answer to the question, 'Do GCS organizations have shared understanding of their values, ethics, and principles of conduct?' To answer this question, I surveyed the views of a slice of GCS actors and content-analyzed their codes of conduct. The questionnaire items and questions for the content-analysis were designed to inquire into the views of GCS actors about characteristics of GCS, as well as about 
their values, ethics, and the rules of conduct. I also examined the collected data in light of the current debates on GCS in order to link findings of the study to the existing theoretical and empirical knowledge on GCS.

The analysis of the survey responses and codes of conduct highlighted many similarities in the ways GCS organizations of different forms and origins define their goals, values, ethical standards, and responsibilities. With regard to their ethical and operating principles, for example, the majority of surveyed organizations (80-90\%) expressed their awareness of the requirements of accountability, transparency, responsible action, and alike. The commonality of normative themes is a big step toward the creation of global civil consciousness and global civil identity of civil society organizations, which, through their collective effort, have reached at least a minimum consensus relating to binding values and irrevocable standards of good practices.

On a less optimistic side, the normative consensus discerned in this study is limited to a particular, liberal, view of GCS. The values of human rights, solidarity, diversity, and consent, and principles of transparency and accountability are traditionally associated to liberal democracy. GCS as understood by the survey respondents and signatories of the codes carry a liberal program. The GCS actors acting in this realm take on non-governmental, non-economic, voluntary, non-hierarchical, and other characteristics contrasted to the power- and profit- driven system of states and markets.

Such a reading of GCS neglects the various forms of contestation for power, pressure, and coercion that exist within global associational life. It draws our attention away from an increasingly important task of examining the influence and appeal of the numerous anti-liberal groups that operate in the global realm (Kenny and Germain, 
2005.). The task of the future analyses, then, is to inquire into the simultaneous presence, of the 'bright' and 'dark' sides in the global space, and survey the contradictions and tensions that emerge from the power imbalances that exist within transnational spaces.

\section{Notes}

${ }^{1}$ www.idealist.org (accessed August 2004).

${ }^{1}$ http://www.interaction.org/members/index.htm (accessed July 2004).

${ }^{1}$ http://www.ngonet.org (accessed July 2004).

${ }^{1}$ In 2003, a total of 14,939 secretariats of international non-governmental organizations (INGOs) and internationally oriented NGOs were located in the high-income countries compared to 3,013 secretariats hosted by the low- and middle-income states (UIA, 2003; Anheier, et al., 2004, 302). A number of empirical studies have pointed out that differences in the approaches and views of civil society organization on global governance tally with their geographic location in either the 'Northern' or 'Southern' part of the world (see, e.g., Clark et al., 1996; Krut, 1997; Pianta and Silva 2003, p.16). If the differences exist, the responses received from a random sample of GCS actors will be biased toward the views of Northern organizations.

\section{References}

Ammore L. \& Langley, P. (2004) Ambiguities of global civil society, Review of International Studies 30, pp.89-110.

Anheier, H., Glasius, M. \& Kaldor M. (2004) (Eds) Global Civil Society 2004/5, pp. 322-335 (London: Sage).

Anheier, H. \& Stares S. (2002) Introducing the global civil society Index, In: H.Anheier et al. (Eds) Global Civil Society 2002, pp.241-254 (Oxford, UK: Oxford University Press). 
Omelicheva, Mariya Y. Values and Ethics of Global Civil Society Actors: Insights from a Survey and Content Analyses, Journal of Civil Society 2(3):233-249, 2006. Publisher's Official Version: <http://dx.doi.org/ 10.1080/17448680601104303>. Open Access Version: <http://kuscholarworks.ku.edu/dspace/>.

\section{Journal of Civil SocietyVol. 2, No. 3, 233-247, December 2006}

An-Na'im, A. (2002) Religion and global civil society: inherent incompatibility or synergy and interdependence?' In: H. Anheier et al. (Eds) Global Civil Society 2002, pp.55-73 (Oxford, UK: Oxford University Press).

Baker, G. \& Chandler, D. (2005) Introduction: global civil society and the future of world politics, In: G. Baker \& D. Chandler (Eds) Global Civil Society: Contested Features, pp.1-15 (New York, NY: Routledge) Bartelson, J. (2006) Making sense of global civil society. European Journal of International Relations 12(3), pp.375-395.

Benchmark Environmental Consulting (1996) Democratic Global Governance (Oslo: Royal Ministry of Foreign Affairs).

Buzan B. (2004) From International to World Society? English School Theory and the Social Structure of Globalization (Cambridge University Press).

Chandhoke, N. (2002) The limits of global civil society, In: H.Anheier et al. (Eds) Global Civil Society 2002, pp.35-53 (Oxford, UK: Oxford University Press).

Clark, A.M, Friedman E.J. \& Hochstetler K. (1998) The sovereign limits of global civil society, World Politics 51(1), pp.1-38.

Cohen, J.L. \& Arato, A. (1992) Civil Society and Political Theory (Cambridge, Mass.: MIT Press).

Colás, A. (2005) Global civil society: analytical category or normative concept? In: G. Baker \& D. Chandler (Eds) Global Civil Society: Contested Features, pp.17-34 (New York, NY: Routledge) Colás, A. (2002) International Civil Society: Social Movements in World Politics (Cambridge: Polity).

DOSA (2004) Capacity and success factors. Available at http://www.edc.org/GLG/CapDev/dosafile/capareas.htm (accessed 1 June 2004).

Dryzek, J.S. (1996) Political inclusion and the dynamics of democratization, American Political Science Review 90(3), pp.475-487.

Edwards, M. (2001) Introduction, in M. Edwards \& J. Gaventa (Eds) Global Citizen Action, pp.1-17 (Boulder, Colo.: Lynne Rienner Publishers).

Falk, R. (1998) Global civil society: perspectives, initiatives, movements, Oxford Development Studies 26(1), pp.99-110. 
Omelicheva, Mariya Y. Values and Ethics of Global Civil Society Actors: Insights from a Survey and Content Analyses, Journal of Civil Society 2(3):233-249, 2006. Publisher's Official Version: <http://dx.doi.org/ 10.1080/17448680601104303>. Open Access Version: <http://kuscholarworks.ku.edu/dspace/>.

\section{Journal of Civil SocietyVol. 2, No. 3, 233-247, December 2006}

Florini, A.M (2001) Transnational Civil Society, In: M. Edwards \& J. Gaventa (Eds) Global Citizen Action, pp.29-43 (Lynne Rienner Publishers).

Gordenker, L. \& Weiss T.G. (1995) Pluralizing global governance: analytical approaches and dimensions, In: T. Weiss \& L. Gordenker (Eds) NGOs, the UN and Global Governance, pp.17-51 (Boulder, Colo.: Lynne Rienner Publishers, Inc.).

Grugel, J. (2002) Democratization: A Critical Introduction. New York: Palgrave.

Howell, J. \& Pearce, J. (2000) Civil society: technical instrument or social force for change, In: D.Lewis \& T. Wallace (Eds) New Roles and Relevance: Development NGOs and the Challenge of Change, pp.75-89 (West Hartfort, Conn.: Kumarian Press).

Kaldor, M. (2003) Global Civil Society: An Answer to War (Cambridge: Polity).

Kenny, M. \& R. Germain (2005) The idea(1) of global civil society, In: R.Germain \& M. Kenny (Eds) The Idea of Global Civil Society: Politics and Ethics in a Globalizing Era, pp.1-17 (New York. NY: Routledge).

Krut, R. (1997) Globalization and civil society: NGO influence in international decision-making. Discussion Paper No.83. (April). Available at http://www.rrojasdatabank.org/toc83.htm (accessed 5 June 2004).

Kunugi, T. \& Schweitz, M. (Eds) (1999) Codes of Conduct for Partnership in Governance: Texts and Commentaries (The United Nations University Press).

Lipschutz, R. (1992) Reconstructing world politics: the emergence of global civil society, Millennium: A Journal of International Studies 21(3), pp.405-406.

Lipschutz, R. with Rowe, J.K. (2005) Globalization, Governmentality and Global Politics: Regulation for the Rest of Us? (New York, NY: Routledge).

Naidoo, K. \& Heinrich, V.H. (2000) Global civil society and the challenges of the new millennium: implications for civil society in Africa, Paper prepared for the Civil Society in Africa Panel at the ISTR conference. Trinity College. Dublin (July 5-8) Available at www.stfx.ca/coady-library/naidoo.htm (accessed 3 July 2004).

Nardin, T. (2000) Private and public roles in civil society, In: M. Walzer (Ed) Toward a Global Civil Society pp.29-35 (New York: Berghahn Books). 


\section{Journal of Civil SocietyVol. 2, No. 3, 233-247, December 2006}

Pasha M.K. \& Blaney D. (1998) Elusive paradise: the promise and peril of global civil society, Alternatives, 23, pp.417-50.

Pianta, M. \& Silva F. (2003) Globalizers from below: a survey on global civil society organizations.

GLOBI Research Report, Lunaira, Tavola della Pace. Available at http://italy.peacelink.org/pace/docs/1172138 gfbweb.pdf (accessed 3 June 2004).

Raustiala, K. (1997) States, NGOs, and the international environmental institutions, International Studies Quarterly 41(4), pp.719-740.

Rosenau, J. N. (1998) Powerful tendencies, enduring tensions and glaring contradictions: the United Nations in a turbulent world, In: A. Paolini et al. (Eds) Between Sovereignty and Global Governance: The United Nations, the State, and Civil Society, pp.252-273 (New York: St. Martin's Press).

Scholte, J. A. (1999) Global civil society: changing the world? Centre for the Study of Globalization and Regionalization Working Paper No.31/99 (Warwick: University of Warwick).

Scholte, J. A. (2001) Civil society and democracy in global governance, Center for the Study of Globalization and Regionalization Working Paper No. 65/01 (Warwick: University of Warwick).

Seckinelgin, H. (2002) Civil society as a metaphor for Western liberalism, Global Society 16(4), pp.357376.

Shaw, M. (1994) Civil society and global politics: beyond a social movements approach, Millennium: Journal of International Studies 23(3), pp.647-667.

Taylor, C. (1991) Civil society in the western tradition, In: E. Groffier \& M. Paradis (Eds) The Notion of Tolerance and Human Rights: Essays in Honor of Raymond Klibansky, pp.117-136 (Ottawa: University of Carleton Press).

Union of International Associations (2001) Yearbook of International Organizations: Guide to Civil Society Networks (Brussels: UIA).

Walzer, M. (1995) The concept of civil society, In: M. Walzer (Ed) Toward a Global Civil Society, pp.7-29 (Berghahn Books).

Warkentin, C. (2001) Reshaping World Politics: NGOs, the Internet, and Global Civil Society (Rowman \& Littlefield Publishers, Inc.) 
White, G. (1994) Civil society, democratization and development: clearing the analytical ground, Democratization 1, pp.375-390.

\section{Appendix}

Framework for Analysis of the Codes of Conduct

The codes of conduct were content analyzed on the presence of themes corresponding to the questions included into the questionnaire. In each of the examined documents, I looked for and coded answers to the following questions:

Characteristics of global civil society actors. Does the code characterize GCS actors as (a) non-for-profit; (b) non-political; (c) autonomous; (d) voluntary; (e) 'civil'; and (f) having some institutional presence; and (g) others?

Characteristics of global civil society. Does the code make references to any of the following aspects of the environment in which GCS actors operate: (a) equality of actors; (b) diversity of actors; (c) common values; (d) common understanding of duties and responsibilities; (e) cooperation and partnership among civil society actors, and (f) others.

Values of global civil society actors. Does the code appeal to any of the following values of GCS actors: (a) respect for individual human rights and freedoms; (b) respect for culture and history; (c) respect for religion; (d) respect for diversity; (e) participatory democracy; (f) peaceful and non-violent orientation; (g) gender equality; and (h) others.

Ethics of global civil society actors. Does the code stipulate that GCS actors should be (a) open and transparent; (b) accountable to any of the following: people they 
serve, funding agencies, and government; (c) respectful of the laws of any jurisdiction in which they operate; (d) respectful of other GCS actors; and (e) others.

Governance of global civil society actors. Does the code require GCS actors to have a clear mission, written policies regarding governance, and rules of conduct? Does the code lay out requirements about the governing structure of GCS actors? What are the requirements for the leadership of GCS actors?

Operating principles. What kind of accountability mechanisms does the code require GCS actors to adopt? Are their any requirements with regard to organizations' projects and programs, such as economic, political, ecological, and cultural sustainability of the projects? Are their any requirements concerning communications with and involvement of different types of constituencies? 